\title{
Evaluation of the Association of Plasma Pentraxin 3 Levels with Type 2 Diabetes and Diabetic Nephropathy in a Malay Population
}

\author{
Norhashimah Abu Seman, ${ }^{1,2}$ Anna Witasp, ${ }^{3,4}$ Wan Nazaimoon Wan Mohamud, ${ }^{2}$ \\ Björn Anderstam, ${ }^{4}$ Kerstin Brismar, ${ }^{1}$ Peter Stenvinkel, ${ }^{4}$ and Harvest F. Gu ${ }^{1}$ \\ ${ }^{1}$ Rolf Luft Research Center for Diabetes and Endocrinology, Department of Molecular Medicine and Surgery, \\ Karolinska University Hospital, Solna, Karolinska Institutet, SE-17176 Stockholm, Sweden \\ ${ }^{2}$ Cardiovascular, Diabetes and Nutrition Research Centre, Institute for Medical Research, Jalan Pahang, 50588 Kuala Lumpur, Malaysia \\ ${ }^{3}$ Center for Molecular Medicine, Karolinska Institutet, SE-17176 Stockholm, Sweden \\ ${ }^{4}$ Division of Renal Medicine, Department of Clinical Science, Intervention and Technology, Karolinska University Hospital, \\ Huddinge, Karolinska Institutet, SE-14157 Stockholm, Sweden
}

Correspondence should be addressed to Norhashimah Abu Seman; norhashimah.abu.seman@ki.se and Harvest F. Gu; harvest.gu@ki.se

Received 15 August 2013; Revised 25 September 2013; Accepted 27 September 2013

Academic Editor: Keizo Kanasaki

Copyright (c) 2013 Norhashimah Abu Seman et al. This is an open access article distributed under the Creative Commons Attribution License, which permits unrestricted use, distribution, and reproduction in any medium, provided the original work is properly cited.

\begin{abstract}
Recent reports have demonstrated that elevated plasma long pentraxin 3 (PTX3) levels are associated with cardiovascular and chronic kidney diseases. In the current study, we investigated the plasma PTX3 levels in 296 Malay subjects including the subjects with normal glucose tolerance (NGT) and type 2 diabetes (T2DM) patients with or without DN by using an enzyme-linked immunesorbent assay. Results showed that in males, plasma PTX3 levels in T2DM patients without DN were lower than that in the subjects with NGT (2.78 versus $3.98 \mathrm{ng} / \mathrm{mL} ; P=0.021$ ). Plasma PTX3 levels in T2DM patients with DN were decreased compared to the patients without DN (1.63 versus $2.78 \mathrm{ng} / \mathrm{mL} ; P=0.013$ ). In females, however, no significant alteration of plasma PTX3 levels among NGT subjects and T2DM patients with and without DN was detected. Furthermore, an inverse correlation between PTX3 and body mass index was found in male subjects with NGT $(P=0.012 ; r=-0.390)$, but not in male T2DM patients, neither in all females. The current study provided the first evidence that decreased plasma PTX3 levels are associated with T2DM and DN in Malay men and also suggested that PTX3 may have different effects in DN and chronic kidney diseases.
\end{abstract}

\section{Introduction}

Type 2 diabetes (T2DM) and obesity have become epidemic in Malaysia. According to the latest National Health and Morbidity Surveys, $14.9 \%$ of Malaysian adults aged 30 years and above are diabetic and they are often obese or overweight $[1,2]$. Moreover, diabetic nephropathy (DN) is the most common cause of end-stage renal disease (ESRD) and contributes to $57 \%$ of patients with T2DM in this country. Although T2DM represents a preventable and treatable cause of ESRD, the number of ESRD cases caused by T2DM has increased and accounts for more than $50 \%$ of incident dialysis patients [3-5]. The public burden from diabetes and DN is enormous.
Pentraxin 3 (PTX3) is an acute-phase glycoprotein and a soluble receptor acting as an opsonin. PTX3 protein is expressed in vascular endothelial cells and macrophages. Thereby, its levels may reflect more directly the inflammatory status of the vasculature [6,7]. Recently, several clinical investigations have demonstrated that elevated plasma PTX3 levels are associated with cardiovascular $[8,9]$ and chronic kidney diseases (CKD) $[10,11]$. Furthermore, plasma PTX3 levels are inversely associated with body mass index (BMI) suggesting that PTX3 may play a role in obesity and metabolic syndrome $[12,13]$. Interestingly, with the approach of genome-wide scan and linkage analysis, chromosome $3 \mathrm{q}$ is found to be linked with diabetes and DN in many ethnic groups [14-16]. 
The gene encoding for PTX3 protein is located in chromosome 3q25.32 and resides in the linkage region. Yilmaz et al. have shown that PTX3 is positively associated with proteinuria in Turkish subjects with T2DM hypertensive patients, while renin angiotensin system blockade lowers plasma PTX3 levels in the patients $[17,18]$. However, there are gender and racial differences of plasma PTX3 levels $[7,19]$, by which the association of PTX3 with kidney dysfunction may be influenced.

In the present study, we examined plasma PTX3 levels in a Malay cohort, including NGT subjects, T2DM patients with and without DN. We also analyzed plasma PTX3 levels according to BMI. The aim of our study was to investigate the association of plasma PTX3 levels with T2DM and DN in this Malay population. Data from our study are also useful for better understanding the different effects of PTX3 in DN and CKD.

\section{Patients and Methods}

2.1. Patients and Controls. Malaysia is a country with multicultures and multiethnic populations. We collected the samples of subjects with NGT and patients with T2DM from the collaborating centers all over Malaysia. The ethnic distribution of our study subjects was $67.6 \%$ Malay, $15.3 \%$ Indian, $14.8 \%$ Chinese, and $2.3 \%$ Indigenous Sabahans and Sarawakians. To avoid the error caused by ethnic stratification, Indian, Chinese, Indigenous Sabahans, and Sarawakians were excluded in the present study. Finally, 103 (50 males/53 females) Malay individuals with NGT (controls) and 193 (99/94) Malay patients with T2DM (cases) were included into the analyses. Diagnoses of T2DM were done based on the World Health Organization (WHO) criteria [20]. The diagnoses of $\mathrm{DN}$ were based on urine albumin-tocreatinine ratio (ACR) suggested by ADA [21]. The patients with T2DM and normoalbuminuria (ACR $<3.5 \mathrm{mg} / \mathrm{mmol}$ ) were considered as controls for $\mathrm{DN}$, while the patients with macroalbuminuria (ACR $\geq 35 \mathrm{mg} / \mathrm{mmol}$ ) and ESRD who needed dialysis were included as the cases for DN. Except for the patients with ESRD, all other subjects were required to give urine under fasting conditions early in the morning. Clinical characteristics of all Malay subjects with NGT and T2DM with and without DN are summarized in Table 1.

All subjects answered a set of questionnaires and underwent clinical and physical examinations. Informed consent was obtained from all subjects, and the study was approved by the local ethical committees. Data and materials transfer agreement from the Institute for Medical Research, Malaysia to Karolinska Institutet, Sweden was signed prior to the study.

2.2. Clinical Characterization. Body weight and height were measured using a calibrated digital scale (Seca, Birmingham, $\mathrm{UK})$. The WHO/International Association for the Study of Obesity (IASO)/International Obesity Task Force (IOTF) has proposed BMI cut-off values of $23.0-24.9 \mathrm{~kg} / \mathrm{m}^{2}$ for classification of overweight and of $\geq 25.0 \mathrm{~kg} / \mathrm{m}^{2}$ for obesity for adult Asians [22]. Based on the Malaysian clinical practice guidelines, subjects with BMI value $\geq 23.0 \mathrm{~kg} / \mathrm{m}^{2}$ are considered as overweight [23]. Systolic and diastolic blood pressures were measured using a digital sphygmomanometer (Omron Healthcare, Inc., Lake Forest, USA) after 5 minutes resting. Creatinine in serum and urine were measured using Randox Assayed Multisera (Randox Laboratories Ltd., Crumlin, UK). Urine or serum was mixed with sodium hydroxide in biochemistry analyzer (Selectra E). Creatinine in alkaline solution reacted with picric acid to form a coloured complex. The amount of the complex formed was measured at wavelength of 490 to $510 \mathrm{~nm}$. The reading of complex measured is directly proportional to the creatinine concentration. Estimate of glomerular filtration rate (GFR) in the dialysis patient was calculated by the mean of renal urea and creatinine clearance from a 24-hour urine correction [24].

2.3. Plasma PTX3 Measurement. A total of $25 \mathrm{~mL}$ venous blood samples were collected from each subject early in the morning after an overnight fasting and then stored at $-80^{\circ} \mathrm{C}$. Plasma PTX3 concentrations were determined using a commercial enzyme-linked immunosorbent assay kit (Quantakine DPTX 30; R\&D Systems Inc., Minneapolis, USA). Experiments with the PTX3 assay were carried out according to the manufacturer's instructions. Briefly, $20 \mu \mathrm{L}$ of standard and plasma samples was assayed duplicate in the microtiter plate wells coated with a specific PTX3 monoclonal antibody followed by incubation at room temperature for 2 hours. The wells were then washed four times with a buffered surfactant solution. Anti-PTX3 polyclonal antibody conjugated to alkaline phosphatase was added to each well and incubated for two hours at room temperature. After washing step, $200 \mu \mathrm{L}$ of substrate solution was added to each well followed by incubation for 30 minutes at room temperature. The solution of $2 \mathrm{~N}$ sulfuric acid was added to each well to stop the reaction. Absorbance was measured at $450 \mathrm{~nm}$ with corrections set at $540 \mathrm{~nm}$ using microplate reader. The values of plasma PTX3 levels were extrapolated from a curve drawn using a standard PTX3.

2.4. Statistical Analyses. All data were expressed as mean (95\% CI) for normally distributed variables and as geometric means (95\% CI) for nonnormally distributed variables. The Kolmogorov-Smirnov test was initially used to test the data for normality. Normal probability plots were created and parameter distributions were transformed to the common logarithm for obtaining a normal distribution before performing statistical analysis. The one-way analysis of variance (ANOVA) was used for comparisons involving more than two groups or independent $t$-test for comparison between two groups. Pearson and Spearman analyses were conducted to determine correlations with continuous and noncontinuous variables, respectively. Statistical significance was defined as the $P$ value of below 0.05 . All analyses were performed using PASW Statistic Base 18 (SPSSInc, Chicago, USA). 


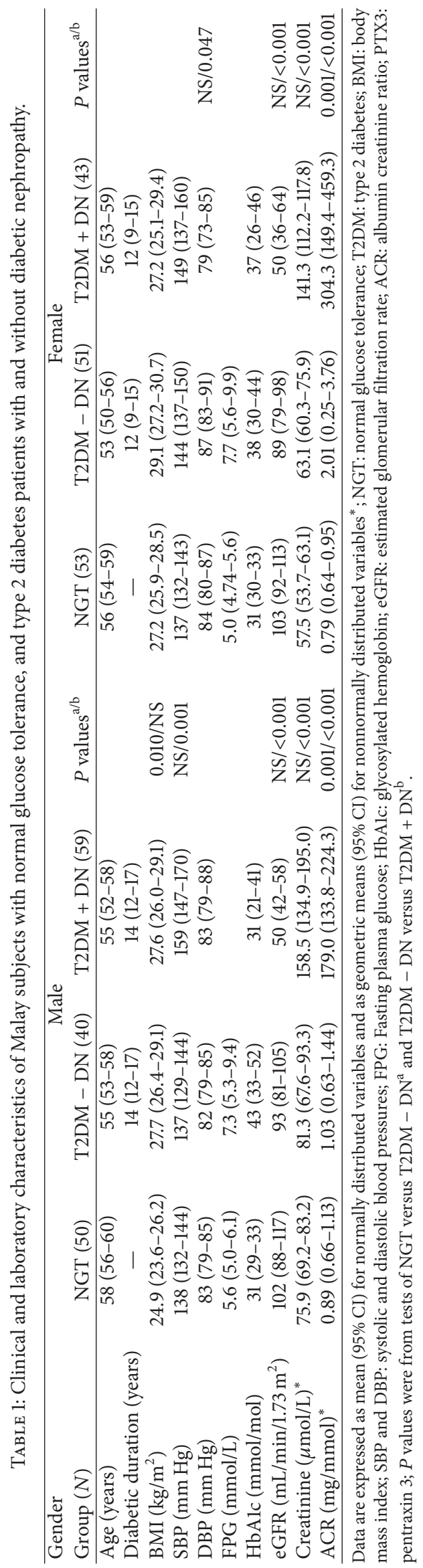




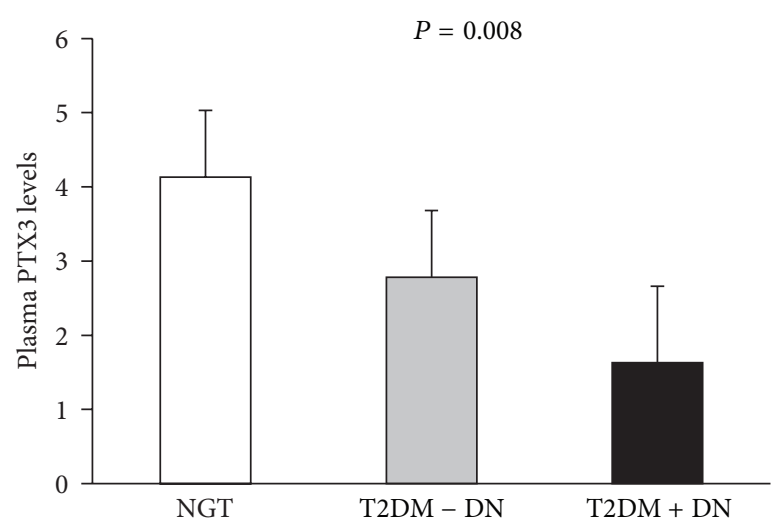

(a) Male

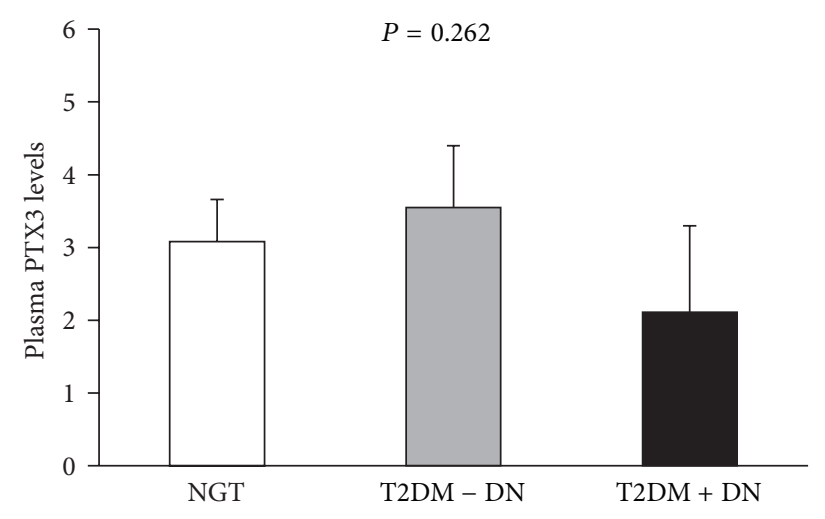

(b) Female

FIGURE 1: Plasma PTX3 levels in Malay subjects with normal glucose tolerance and type 2 diabetes patients with or without diabetic nephropathy. Data presented as means with $95 \%$ CI; $P$ values were from ANOVA tests; NGT: normal glucose tolerance; T2DM: type 2 diabetes; $\mathrm{DN}$ : diabetic nephropathy.

\section{Results}

3.1. Gender Differences of Plasma PTX3 Levels in Malay Subjects. In both males and females, there was no difference in age, waist circumference, and HbAlc between T2DM patients and NGT subjects. Although plasma PTX3 levels in males and females differed significantly, PTX3 had no relationship with age in males $(P=0.647)$ or females $(P=$ 0.626). Thus, all subsequent analyses of plasma PTX3 levels were done separately in males and females. Our analyses indicated that plasma PTX3 levels in T2DM patients with and without DN were lower as compared with NGT subjects in males (2.62 versus $3.98 \mathrm{ng} / \mathrm{mL} ; P=0.021)$ but not in females (3.24 versus $3.09 \mathrm{ng} / \mathrm{mL} ; P=0.748$ ).

3.2. Association of Plasma PTX3 Levels with Type 2 Diabetes and Diabetic Nephropathy. We further analyzed the association of PTX3 with T2DM and DN. Figure 1(a) showed that plasma PTX3 levels were consistently decreased from NGT to T2DM without DN and to the patients with DN in males (3.98, 2.78, and $1.63 \mathrm{ng} / \mathrm{mL} ; P=0.008$ ANOVA test). Among males, the patients with DN had lower PTX3 levels compared to T2DM without DN (1.63 versus $3.08 \mathrm{ng} / \mathrm{mL}$; $P=0.013)$. In females, however, there was no statistically significant difference of the mean values of plasma PTX3 levels among NGT and T2DM with and without DN (3.09, 3.55 , and $2.11 \mathrm{ng} / \mathrm{mL} ; P=0.262$, ANOVA test) (Figure $1(\mathrm{~b})$ ).

3.3. Correlations of Plasma PTX3 Levels with BMI. There was a negative correlation between plasma PTX3 levels and BMI in male subjects with NGT $(r=-0.390 ; P=0.012)$ (Figure 2) but not in females $(P=0.330)$. The correlation between PTX3 and BMI was not found in all male and female T2DM patients with and without DN. In Malaysia, the adults with BMI value $\geq 23.0 \mathrm{~kg} / \mathrm{m}^{2}$ are considered to be overweight [23]. To further understand whether the association between PTX3 and $\mathrm{DN}$ in T2DM was influenced by BMI, we performed the comparative analyses in the patients with overweight

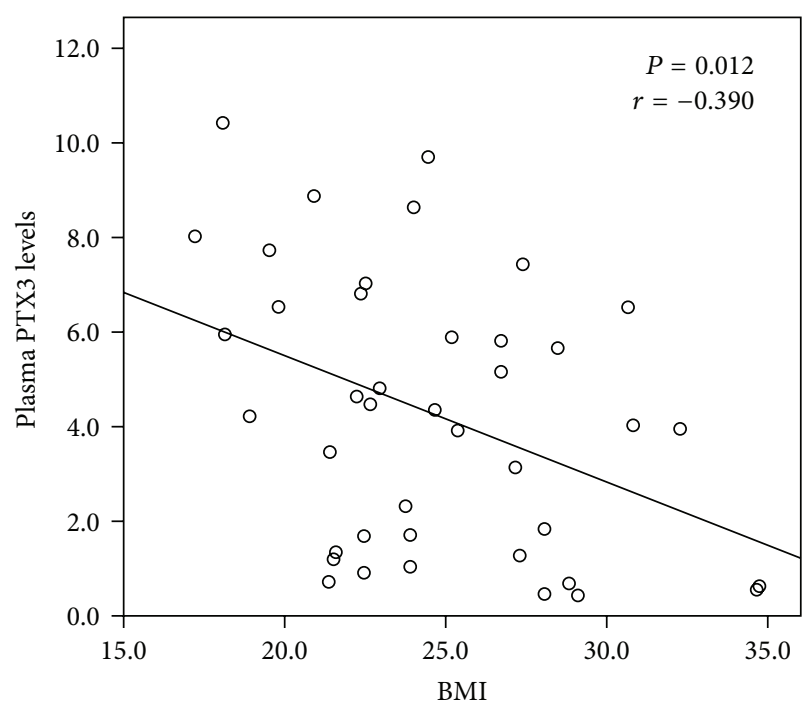

FIgURE 2: Univariate correlation between plasma PTX3 levels and $\mathrm{BMI}$ in Malay men with normal glucose tolerance.

$\left(\right.$ BMI $\left.\geq 23 \mathrm{~kg} / \mathrm{m}^{2}\right)$ and lean patients (BMI $\left.<23 \mathrm{~kg} / \mathrm{m}^{2}\right)$, respectively. In males with overweight, we found that plasma PTX3 levels were gradually decreased from subjects with NGT to T2DM patients without DN and to the patients with $\mathrm{DN}$ (3.68, 2.60 and $1.42 \mathrm{ng} / \mathrm{mL} ; P=0.044$, ANOVA test) (Figure 3). In lean males and also in all females, plasma PTX3 levels of NGT and T2DM with and without DN were varied but not with any statistical significance.

\section{Discussion}

In the present study, we analyzed plasma PTX3 levels in Malay subjects with NGT and T2DM with and without DN. We report a gender difference of plasma PTX3 levels in this population. Lower levels of PTX3 were found to be associated with T2DM and DN in males but not in females. 


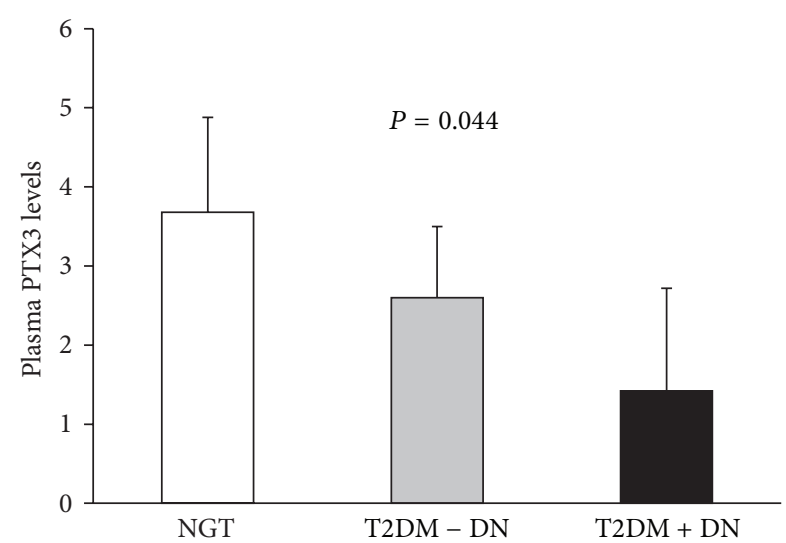

FIGURE 3: Plasma PTX3 levels in overweight Malay men with normal glucose tolerance and type 2 diabetes patients with or without diabetic nephropathy. Data presented as means with 95\% CI; $P$ values were from ANOVA tests; NGT: normal glucose tolerance; T2DM: type 2 diabetes; DN: diabetic nephropathy.

Furthermore, PTX3 was found to be inversely associated with BMI in males with NGT. The correlation was not observed both in males and females with T2DM and DN.

Gender is an important factor for the development of T2DM and DN. Males have a higher prevalence of T2DM and DN in many populations including Malaysians [1, 35]. Epidemiologic reports have demonstrated that $\mathrm{DN}$ is $30 \%$ more frequent in males than in females [25]. Genetic studies have also showed that DNA polymorphisms in the genes of sex-determining region Y-box 2, angiotensin II type 1 , and type 2 receptors are associated with DN with gender-specific effects [26-28]. Previously, Yamasaki et al. observed that plasma PTX3 levels between males and females in a healthy Japanese population are different [7]. In the present study, we demonstrate that plasma PTX3 levels gradually decreased from NGT to T2DM without DN to T2DM with DN particularly among males but not in females. Furthermore, an inverse correlation between PTX3 and BMI was found in male subjects with NGT. This correlation was not seen in all females and males with T2DM and DN. Taking together, data from previous and present studies implicate that PTX3 most likely has gender-specific effects in T2DM and DN, which should be taken into our consideration in further investigations.

Several studies have reported that increased PTX3 levels are associated with impaired renal function in CKD $[10,11]$. The similar association of PTX3 with DN is seen in Turkish patients with T2DM [17]. In the present study, however, we demonstrate that decreased PTX3 levels are associated with DN in Malay men with T2DM. First, the controversy may be caused by the studies in different ethnic populations. Dubin et al. have demonstrated that there are racial differences of PTX3 in term of association with kidney dysfunction [19]. Second, the ages of Turkish T2DM subjects with DN (at 42 years old) [17] are younger and their duration of diabetes are shorter compared to Malay T2DM patients with DN (at the age of 55 years old) in the present study. Furthermore, clinical observations have indicated that two main causes of CKD are diabetes and high blood pressure, which are responsible for up to two-thirds of the cases. The progresses and mechanisms of DN and CKD may be different [29], while PTX3 may have different effects in these two diseases.

We have shown that plasma PTX3 levels were inversely correlated with BMI in males with NGT, which is consistent with previous reports $[7,12,13]$. In the present study, there is a limitation with lack of lean subjects because all patients with T2DM and female subjects with NGT had mean values of BMI at least $27.2 \mathrm{~kg} / \mathrm{m}^{2}$. Recently, a study has demonstrated that PTX3 is expressed in adipose tissue, and its tissue specific expression reflects endothelial dysfunction [30]. Another study has reported that PTX3 is positively correlated with adiponectin [12]. Although we did not analyze plasma levels of adiponectin in this Malay cohort, the accumulated documents have shown that adiponectin is inversely proportional to obesity and T2DM in different populations including Malaysians. Plasma/serum adiponectin levels in the patients with T2DM and obese subjects are decreased compared to that in healthy control subjects [31, 32]. Therefore, we hypothesize that PTX3, as similar to adiponectin, may have protective effects in increased body weight. Further investigation is needed to fully understand the cellular mechanism of $\mathrm{PTX} 3$ reduction in T2DM and $\mathrm{DN}$.

In conclusion, the present study provides the first evidence that decreased plasma PTX3 levels are associated with T2DM and DN in Malay men and also suggests that PTX3 may have different effects in DN and CKD.

\section{Abbreviations \\ ACR: Urine albumin-to-creatinine ratio eGFR: Estimate of glomerular filtration rate \\ DN: Diabetic nephropathy \\ NGT: Normal glucose tolerance \\ T2DM: Type 2 diabetes \\ PTX3: Pentraxin 3.}

\section{Conflict of Interests}

The authors declare that they have no conflict of interests.

\section{Authors' Contributions}

Peter Stenvinkel, Harvest F. Gu, Kerstin Brismar, and Norhashimah Abu Seman proposed and designed the study; Norhashimah Abu Seman, Anna Witasp, and Björn Anderstam collected experimental data; Wan Nazaimoon Wan Mohamud and Norhashimah Abu Seman collected clinical data; Norhashimah Abu Seman and Harvest F. Gu analyzed the data; and Harvest F. Gu, Norhashimah Abu Seman and Peter Stenvinkel wrote the paper. All of the authors contributed to data interpretation, discussion, and revision of the paper. 


\section{Acknowledgments}

The authors wish to thank all Malay subjects who have volunteered to participate in the present study, research colleagues in IMR, Malaysians who were involved in sample collection, and Ms. Monica Eriksson and Ann-Christin Bragfors-Helin in KI for technical support. The study was supported by Stig and Gunborg Westmans Foundation, Karolinska Institute Fond and Family Erling-Persson Foundation. NAS is supported by a scholarship from Ministry of Science, Technology and Innovation, Malaysia.

\section{References}

[1] G. R. Letchuman, W. M. Wan Nazaimoon, W. B. Wan Mohamad et al., "Prevalence of diabetes in the Malaysian national health morbidity survey III 2006," The Medical journal of Malaysia, vol. 65, no. 3, pp. 180-186, 2010.

[2] W. N. W. Mohamud, K. I. Musa, A. S. M. Khir et al., "Prevalence of overweight and obesity among adult malaysians: an update," Asia Pacific Journal of Clinical Nutrition, vol. 20, no. 1, pp. 35-41, 2011.

[3] Y. N. Lim, T. O. Lim, D. G. Lee et al., "A report of the Malaysian dialysis registry of the national renal registry, Malaysia," Medical Journal of Malaysia, vol. 63, no. C, pp. 5-8, 2008.

[4] A. M. Shaza, G. Rozina, M. I. M. Izham, and S. S. S. Azhar, "Dialysis for end stage renal disease: a descriptive study in penang hospital," Medical Journal of Malaysia, vol. 60, no. 3, pp. 320-327, 2005.

[5] L. S. Hooi, H. S. Wong, and Z. Morad, "Prevention of renal failure: the Malaysian experience," Kidney International, Supplement, vol. 67, no. 94, pp. S70-S74, 2005.

[6] P. Cieślik and A. Hrycek, "Long pentraxin 3 (PTX3) in the light of its structure, mechanism of action and clinical implications," Autoimmunity, vol. 45, no. 2, pp. 119-128, 2012.

[7] K. Yamasaki, M. Kurimura, T. Kasai, M. Sagara, T. Kodama, and K. Inoue, "Determination of physiological plasma pentraxin 3 (PTX3) levels in healthy populations," Clinical Chemistry and Laboratory Medicine, vol. 47, no. 4, pp. 471-477, 2009.

[8] R. Dubin, Y. Li, J. H. Ix, M. G. Shlipak, M. Whooley, and C. A. Peralta, "Associations of pentraxin-3 with cardiovascular events, incident heart failure, and mortality among persons with coronary heart disease: data from the heart and soul study," American Heart Journal, vol. 163, no. 2, pp. 274-279, 2012.

[9] M. Tong, J. J. Carrero, A. R. Qureshi et al., "Plasma pentraxin 3 in patients with chronic kidney disease: associations with renal function, protein-energy wasting, cardiovascular disease, and mortality," Clinical Journal of the American Society of Nephrology, vol. 2, no. 5, pp. 889-897, 2007.

[10] M. E. Suliman, M. I. Yilmaz, J. J. Carrero et al., "Novel links between the long pentraxin 3, endothelial dysfunction, and albuminuria in early and advanced chronic kidney disease," Clinical Journal of the American Society of Nephrology, vol. 3, no. 4, pp. 976-985, 2008.

[11] C. L. Meuwese, J. J. Carrero, and P. Stenvinkel, "Recent insights in inflammation-associated wasting in patients with chronic kidney disease," Contributions to Nephrology, vol. 171, pp. 120126, 2011.

[12] T. Miyamoto, A. R. Qureshi, O. Heimbürger et al., "Inverse relationship between the inflammatory marker Pentraxin-3, fat body mass, and abdominal obesity in end-stage renal disease,"
Clinical Journal of the American Society of Nephrology, vol. 6, no. 12, pp. 2785-2791, 2011.

[13] O. Osorio-Conles, M. Guitart, M. R. Chacón et al., "Plasma PTX3 protein levels inversely correlate with insulin secretion and obesity, whereas visceral adipose tissue PTX3 gene expression is increased in obesity," American Journal of Physiology, vol. 301, no. 6, pp. E1254-E1261, 2011.

[14] G. Imperatore, R. L. Hanson, D. J. Pettitt, S. Kobes, P. H. Bennett, and W. C. Knowler, "Sib-pair linkage analysis for susceptibility genes for microvascular complications among pima indians with 2 diabetes," Diabetes, vol. 47, no. 5, pp. 821-830, 1998.

[15] D. W. Bowden, C. J. Colicigno, C. D. Langefeld et al., "A genome scan for diabetic nephropathy in African Americans," Kidney International, vol. 66, no. 4, pp. 1517-1526, 2004.

[16] G. Placha, L. H. Canani, J. H. Warram, and A. S. Krolewski, "Evidence for different susceptibility genes for proteinuria and ESRD in type 2 diabetes," Advances in Chronic Kidney Disease, vol. 12, no. 2, pp. 155-169, 2005.

[17] M. I. Yilmaz, J. J. Carrero, J. L. Martín-Ventura et al., "Combined therapy with renin-angiotensin system and calcium channel blockers in type 2 diabetic hypertensive patients with proteinuria: effects on soluble TWEAK, PTX3, and flow-mediated dilation," Clinical Journal of the American Society of Nephrology, vol. 5, no. 7, pp. 1174-1181, 2010.

[18] M. I. Yilmaz, J. Axelsson, A. Sonmez et al., "Effect of renin angiotensin system blockade on pentraxin 3 levels in type2 diabetic patients with proteinuria," Clinical Journal of the American Society of Nephrology, vol. 4, no. 3, pp. 535-541, 2009.

[19] R. Dubin, M. Shlipak, Y. Li et al., "Racial differences in the association of pentraxin-3 with kidney dysfunction: the multiethnic study of atherosclerosis," Nephrology Dialysis Transplantation, vol. 26, no. 6, pp. 1903-1908, 2011.

[20] WHO, Definition, Diagnosis and Classification of Diabetes Mellitus and Its Complications. Part 1: Diagnosis and Classification of Diabetes Mellitus, WHO/NCD/NCS/99.2, World Health Organization, Geneva, Switzerland, 1999.

[21] M. E. Molitch, R. A. DeFronzo, M. J. Franz et al., "Nephropathy in diabetes," Diabetes Care, vol. 27, supplement 1, pp. S79-S83, 2004.

[22] World Health Organization/International Association for the Study of Obesity/International Obesity Task Force, The AsiaPacific Perspective: Redrfining Obesity and Its Treatment, 2000, http://www.wpro.who.int/nutrition/documents/docs/Redefiningobesity.pdf.

[23] K. C. Cheong, A. F. Yusoff, S. M. Ghazali et al., "Optimal BMI cut-off values for predicting diabetes, hypertension and hypercholesterolaemia in a multi-ethnic population," Public Health Nutrition, vol. 16, no. 3, pp. 453-459, 2013.

[24] S. Herget-Rosenthal, A. Bökenkamp, and W. Hofmann, "How to estimate GFR-serum creatinine, serum cystatin $\mathrm{C}$ or equations?" Clinical Biochemistry, vol. 40, no. 3-4, pp. 153-161, 2007.

[25] A. Moloney, W. M. G. Tunbridge, J. T. Ireland, and P. J. Watkins, "Mortality from diabetic nephropathy in the United Kingdom," Diabetologia, vol. 25, no. 1, pp. 26-30, 1983.

[26] K. Pettersson-Fernholm, S. Fröjdö, J. Fagerudd et al., “The AT2 gene may have a gender-specific effect on kidney function and pulse pressure in type I diabetic patients," Kidney International, vol. 69, no. 10, pp. 1880-1884, 2006.

[27] H. F. Gu, A. Alvarsson, S. Efendic, and K. Brismar, "SOX2 has gender-specific genetic effects on diabetic nephropathy in samples from patients with type 1 diabetes mellitus in the 
GoKinD study," Gender Medicine, vol. 6, no. 4, pp. 555-564, 2009.

[28] R. Retnakaran, C. A. Cull, K. I. Thorne, A. I. Adler, and R. R. Holman, "Risk factors for renal dysfunction in type 2 diabetes: U.K. Prospective Diabetes Study 74," Diabetes, vol. 55, no. 6, pp. 1832-1839, 2006.

[29] T. Z. Min, M. W. Stephens, P. Kumar, and R. A. Chudleigh, "Renal complications of diabetes," British Medical Bulletin, vol. 104, no. 1, pp. 113-127, 2012.

[30] A. Witasp, M. Rydén, J. J. Carrero et al., "Elevated circulating levels and tissue expression of pentraxin 3 in uremia: a reflection of endothelial dysfunction," PLoS ONE, vol. 8, no. 5, Article ID e63493, 2013.

[31] H. F. Gu, "Biomarkers of adiponectin: plasma protein variation and genomic DNA polymorphisms," Biomark Insights, vol. 4, pp. 123-133, 2009.

[32] B. I. Loh, D. R. Sathyasuryan, and H. J. Mohamed, "Plasma adiponectin concentrations are associated with dietary glycemic index in Malaysian patients with type 2 diabetes," Asia Pacific Journal of Clinical Nutrition, vol. 22, no. 2, pp. 241-248, 2013. 


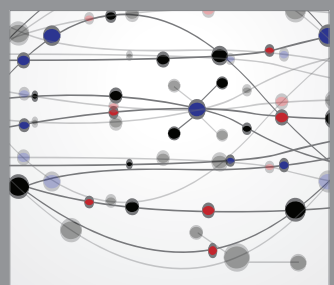

The Scientific World Journal
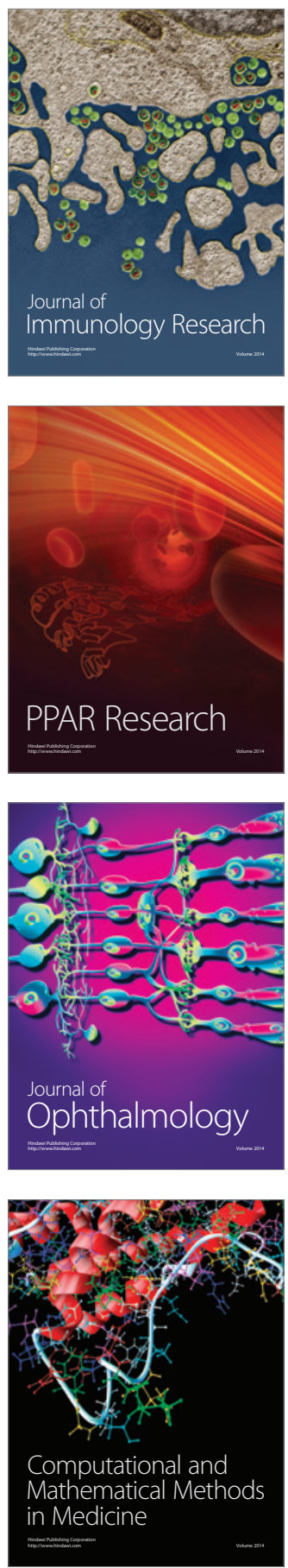

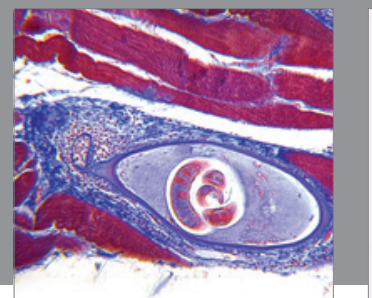

Gastroenterology

Research and Practice
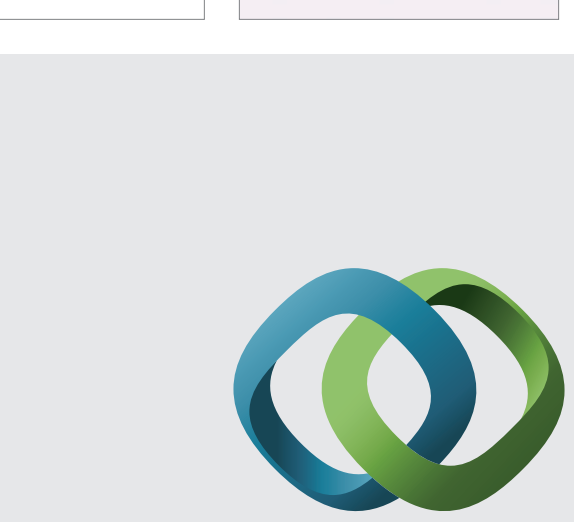

\section{Hindawi}

Submit your manuscripts at

http://www.hindawi.com
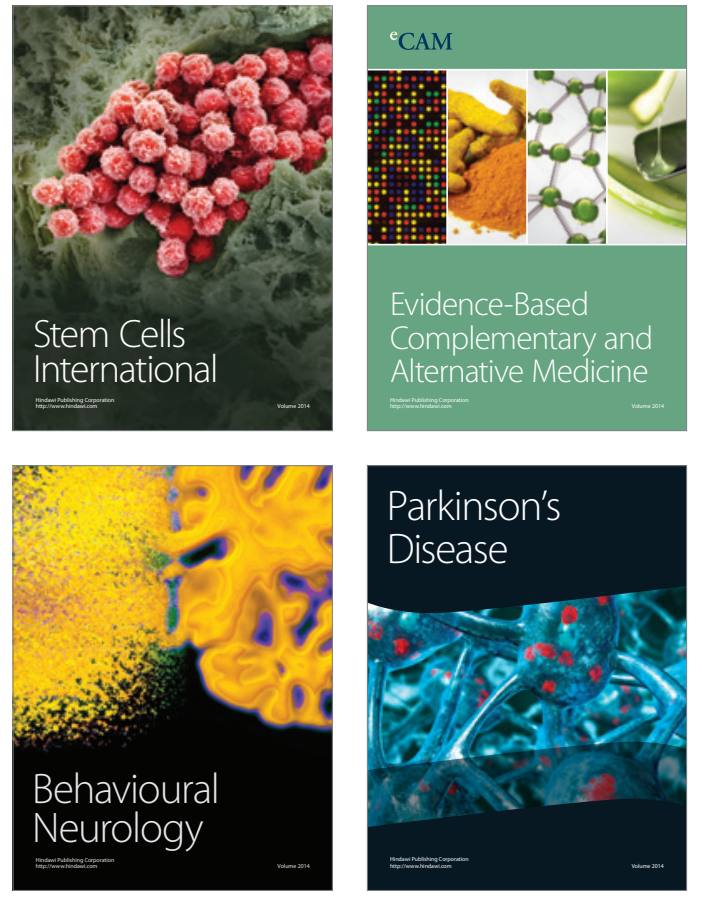
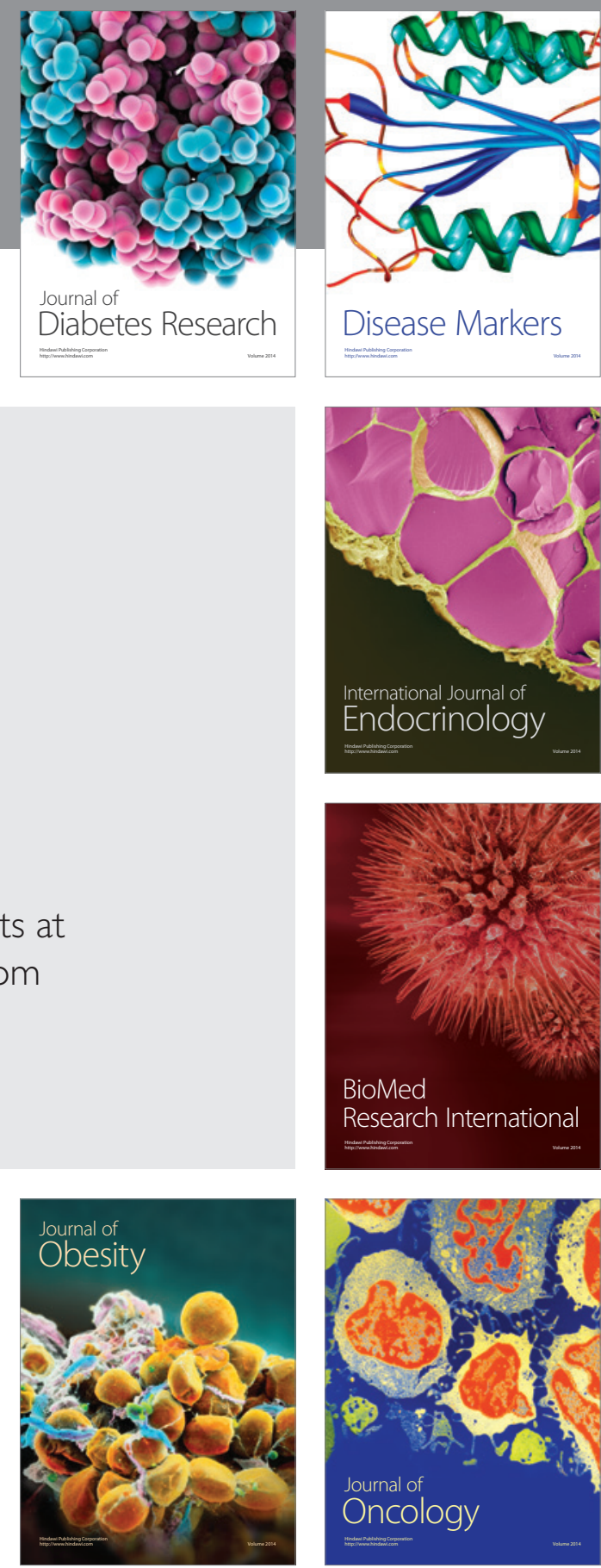

Disease Markers
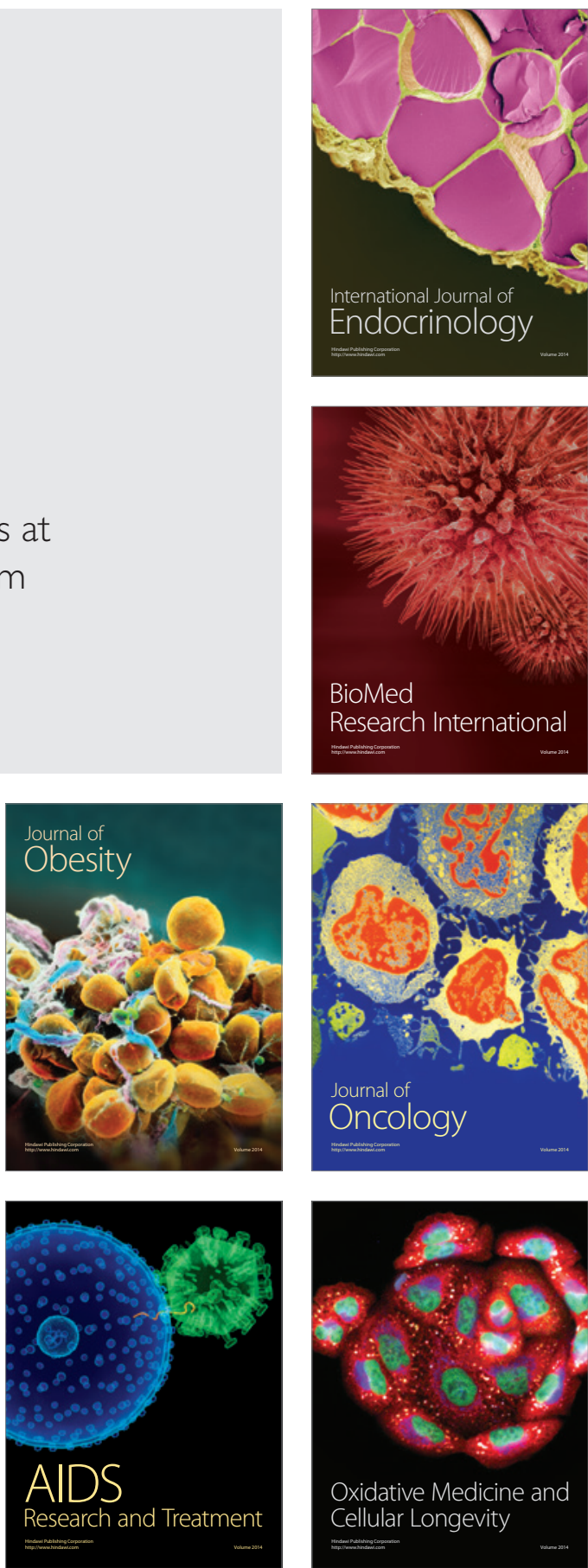